\title{
The mineral content of the hard dental tissue of mesiodens
}

\author{
Sanja Tanaskovic-Stankovic ${ }^{\mathrm{a}}$, Irena Tanaskovic ${ }^{\mathrm{a}}$, Nemanja Jovicic ${ }^{\mathrm{a}}$, Marina Miletic-Kovacevic ${ }^{\mathrm{a}}$, Tatjana Kanjevac ${ }^{\mathrm{b}}$, \\ Zoran Milosavljevic ${ }^{\mathrm{a}}$
}

\begin{abstract}
Objective. Mesiodens is the most common form of supernumerary tooth mainly located between the maxillary central incisors. Its etiology is not completely understood but both genetic and environmental factors are assumed. The degree of mineralization and inorganic element content in hard tooth tissues is poorly understood as well as is the durability and suitability for allo- and auto-transplantation. Therefore aim of this study was to examine the content of inorganic elements.

Materials and Methods. This study included 26 mesiodens teeth and 26 normal central incisor teeth as controls. All specimens were prepared for SEM/EDS analysis which was aimed at specific sites on the enamel, dentine and cementum in order to evaluate the weight percentage and ratio of important inorganic elements.

Results and Conclusion. The results showed that there was a difference in the weight percentage of selected inorganic elements (calcium, phosphorus, oxygen, carbon, magnesium and sodium) in all three types of dental hard tissues but the differences were mostly expressed in the cementum tissue. The statistical analysis showed that the differences were marginally significant especially for calcium and phosphorus values and ratio in the enamel and dentine. The carbon and magnesium content in all three hard tissues showed the most differences, but overall, the hard tissues mineral content of the mesiodens did not differs significantly from healthy teeth.
\end{abstract}

Key words: mesiodens, elemental composition, dentin, enamel, cementum

Received: March 16, 2018; Accepted: April 4, 2018; Available online: May 15, 2018

https://doi.org/10.5507/bp.2018.017

aInstitute for Histology and Embryology, Faculty of Medical Sciences, University of Kragujevac, Serbia

${ }^{b}$ Department of Dentistry, Faculty of Medical Sciences, University of Kragujevac, Serbia

Corresponding author: Zoran Milosavljevic, e-mail: zormil67@medf.kg.ac.rs

\section{INTRODUCTION}

Tooth development is a complex process of mineralization of connective tissues that depends on various genetic control mechanisms and biochemical cellular reactions. Supernumerary teeth have become interesting to clinicians and researchers in last decade due to their auto- and allo-transplantation potential as well as a good source of stem cells ${ }^{1-3}$. The overall prevalence of the supernumerary tooth in permanent dentition is from $1.5-3.5 \%$ and mesiodens contribute around $80 \%$ of cases $\left(\right.$ ref. $\left.^{4}\right)$. Mesiodens is the most common form of the supernumerary tooth mainly located just between the maxillary central incisors $^{5}$. Often the mesiodens has a typical appearance (conical shape) and with all morphological characteristics of the normal tooth, but it sometimes is atypical with altered form as a result of defective development from the remnants of the tooth bud ${ }^{6,7}$. Both, genetic and environmental, factors have been considered and several different theories such as the atavism, dichotomy theory and genetic syndromes have been suggested to explain the occurrence of the mesioden $\mathrm{s}^{8-10}$. Regardless of the reason, its development follows that of other normal permanent teeth, while its mineralization frequently occurs later than homologous teeth which means that inductive factors (stimuli) for mesiodens teeth are weaker and somewhat impaired $^{11,12}$. A number of studies have shown that the normal tooth possess calcium $(\mathrm{Ca})$, phosphorus $(\mathrm{P})$, and oxygen $(\mathrm{O})$, as indicated by the formula for hydroxyapatite (HAP), also carbon (C), magnesium $(\mathrm{Mg})$, sodium $(\mathrm{Na})$, as well as several trace elements ${ }^{13-15}$. On the other hand, a survey of the literature related to the mineral content of the supernumerary teeth as well as mesiodens provided no results. Given that, the degree of mineralization, ratio of inorganic elements as well as the presence of trace elements in hard dental tissues of the mesiodens are important facts when susceptibility to tooth decay and erosion are evaluated, the aim of our study was to examine the mineral content of the enamel, dentin and cementum of the mesiodens.

\section{MATERIAL AND METHODS}

All procedures in the study were approved by the Ethics Committee. The study included 26 mesiodens teeth and 26 central incisor teeth. All specimens were obtained from different patients. Clinical diagnosis of the mesiodens was confirmed with X-ray imaging and these teeth, extracted for esthetic or orthodontic reasons, were used as the experimental group, while the control group consisted of central incisor teeth extracted for orthodontic reasons. Teeth from both groups were from the permanent dentition, from healthy patients of both sexes without caries, periapical granulomas and orthodontic treatment. Patients were 25-50 years of age from whom we received 

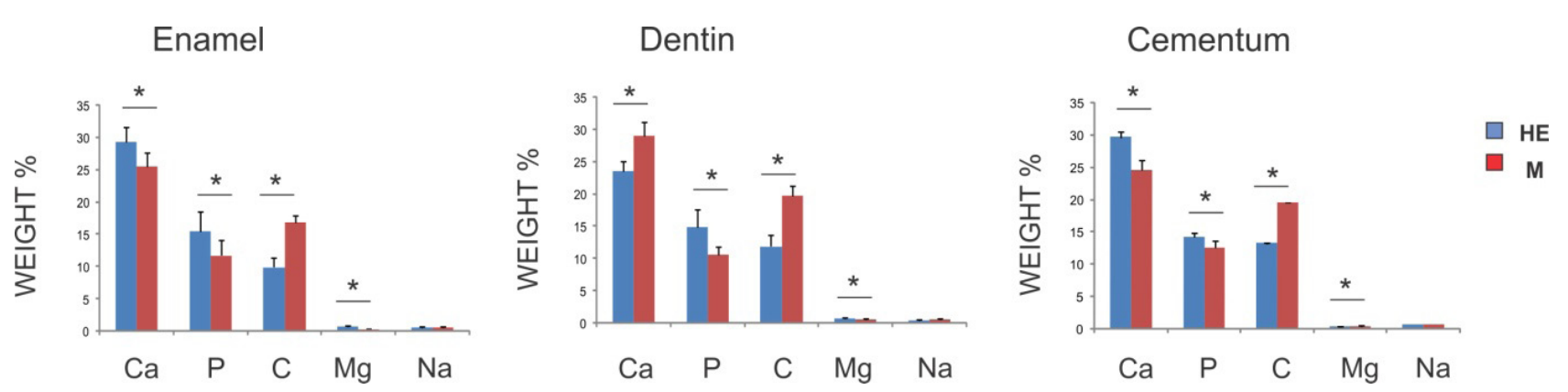

Fig. 1. Distibution ofbasic chemical elements in healthy and mesiodens enamel, dentine and cementum in weight percentage. HE- healthy teeth; M-mesiodens; $(*)$-significantly

written consent to participate in the study and who had previously been fully informed, orally and in writing, about the aims of the study. During the initial preparation of samples, the teeth were cut into a lingual and labial part and separated using a diamond disc with constant cooling at the speed of $6000 \mathrm{rev} / \mathrm{min}$. The surface of the obtained parts was first polished with fine silicon carbide paper and then with diamond paste. Diamond polishing was essential to remove the debris and to obtain glossy surfaces needed for a quantitative chemical analysis. The enamel surface of each tooth was polished for 5 min with a rubber cup mounted at a low-speed hand piece (KaVo, Biberach, Germany) and under constant deionized water irrigation in order to remove the remnants of the carbide paper. Abrasive substances were not used. Finally, the teeth were rinsed again in an ultrasonic bath before storing them in labeled plastic tubes with $10 \%$ formalin solution for 3 days for further analysis. Although fixing solution for a prolonged period could affect the mineral composition of the teeth, in our experiment the fixation period was too short to manifest that effect.

\section{Energy dispersive spectrometry (EDS) analysis}

Energy dispersive spectrometry is a specific method for determining the concentration of chemical elements in the substratum. Samples for the EDS analysis were previously cleaned by ethanol and kept in an ultrasonic bath for a several minutes and then air dried. The samples were then fixed on a holder with carbon paste (to the bottom of the specimens) and gold vapor was applied, so that the surface would be electron transparent for the penetrating electron beam. Such samples were then analyzed with scanning electron microscope equipped with energydispersive system for EDS analyses. The analysis of the chemical elements of the enamel, dentin and cementum was performed in the Laboratory for Scanning Electron Microscopy with Energy-Dispersive Spectrometry (SEMEDS) Surface of the specimens was examined by means of a scanning electron microscope (SEM) type JEOL JSM$6610 \mathrm{LV}$ at $20 \mathrm{kV}$. Relative amounts of the measured chemical elements were calculated using Energy-Dispersive System-EDS, model XMax Large Area Analytical Silicon Drift connected with INCA Energy 350 Microanalysis System, with the detection limit of 0.1 mass percentages and resolution of $126 \mathrm{eV}$. Optimal magnification was set on 500. The SEM/EDS analysis was directed to specific regions of the teeth: for the enamel the three sites selected were (the surface, $0,5 \mathrm{~mm}$ below the surface and $0.5 \mathrm{~mm}$ distal from the dentin-enamel junction). For dentin crown and root parts were selected and for cementum $0,1 \mathrm{~mm}$ from the root apex. In order to assure the same location of analysis for all the specimens, selection of every line of interest was performed by aiming the EDS X-ray at the exact same distance from the marker point (e.g. tooth surface, enamel-dentin junction and root apex) on the low-power microscopic image of the examined tooth.

\section{Statistics}

Quantitative analysis of the distribution of chemical elements in enamel, dentin and cementum were done by applying "dotted" analysis at a previously determined line of analysis. The chemical and elemental composition of each tooth samples were tested for normal distribution (Gaussian distribution) using the Shapiro-Wilk test. The following were used to process the: Mann-Whitney U-test, Student t-test and $\mathrm{X}^{2}$ test. The level of significance was set as $(P<0.05)$. The results are presented as means \pm standard deviation (SD). For statistical analysis SPSS, IBM Analytics, USA software, version 22.0 was used.

\section{RESULTS}

Results of the comparative quantitative analysis of the basic chemical elements (plus oxygen whose content had been calculated by stoichiometric calculations) in hard tissues of the healthy teeth and mesiodensare displayed in Table 1.

\section{Enamel analysis}

Analysis of healthy enamel showed that the mean value of Ca concentration was $29.33 \mathrm{wt} \%$ whereas the mean value of calcium concentration in mesiodens enamel was $25.59 \mathrm{wt} \%$. It was observed that the concentration of calcium was significantly higher in healthy enamel compared to mesiodens enamel $(P<0.05)$. The mean value of phosphorus concentration in the enamel of the teeth from the control group was $15.46 \mathrm{wt} \%$ and in mesiodens enamel $11.78 \mathrm{wt} \%$. Carbon concentration was statistically significantly higher in mesiodens enamel compared to healthy enamel $(P<0.05)$. Regional distribution of the carbon showed that the concentration of this element sharply decreased from the dentin-enamel border towards the surface (Table 2). The mean value of magnesium 
Table 1. EDS results from enamel, dentine and cementum.

\begin{tabular}{lrrrrrr}
\hline ELEMENT & \multicolumn{2}{c}{ ENAMEL } & \multicolumn{2}{c}{ DENTIN } & \multicolumn{2}{c}{ CEMENTUM } \\
& \multicolumn{1}{c}{ HE } & \multicolumn{1}{c}{$\mathrm{M}$} & \multicolumn{1}{c}{ HE } & \multicolumn{1}{c}{$\mathrm{M}$} & \multicolumn{1}{c}{ HE } & $\mathrm{M}$ \\
\hline Calcium (\%) & $29.33 \pm 2.33$ & $25.59 \pm 2.01$ & $23.55 \pm 1.55$ & $29.10 \pm 2.03$ & $29.62 \pm 1.44$ & $24.54 \pm 1.51$ \\
Phosphorus (\%) & $15.46 \pm 3.04$ & $11.78 \pm 2.26$ & $14.94 \pm 2.62$ & $10.59 \pm 1.26$ & $14.17 \pm 0.87$ & $12.47 \pm 1.60$ \\
Carbon (\%) & $9.95 \pm 1.40$ & $20.64 \pm 2.18$ & $11.93 \pm 1.76$ & $19.78 \pm 1.52$ & $13.21 \pm 0.71$ & $19.50 \pm 1.10$ \\
Oxygen (\%) & $44.48 \pm 1.95$ & $44.15 \pm 2.10$ & $48.15 \pm 2.59$ & $39.33 \pm 2.64$ & $41.96 \pm 1.02$ & $42.28 \pm 1.89$ \\
Magnesium (\%) & $0.72 \pm 0.16$ & $0.35 \pm 0.12)$ & $0.76 \pm 0.14$ & $0.60 \pm 0.11$ & $0.28 \pm 0.06$ & $0.34 \pm 0.12$ \\
Sodium (\%) & $0.58 \pm 0.10$ & $0.61 \pm 0.11$ & $0.48 \pm 0.07$ & $0.59 \pm 0.10$ & $0.68 \pm 0.12$ & $0.62 \pm 0.21$ \\
Ca/P ratio & $1.97 \pm 0.55$ & $2.26 \pm 0.50$ & $1.63 \pm 0.35$ & $2.78 \pm 0.38$ & $2.10 \pm 0.19$ & $2.00 \pm 0.30$ \\
Ca/C ratio & $3.02 \pm 0.49$ & $1.53 \pm 0.15$ & $2.23 \pm 0.37$ & $1.48 \pm 0.17$ & $2.25 \pm 0.21$ & $1.26 \pm 0.12$ \\
\hline
\end{tabular}

Data in weight \%. HE - healthy teeth group; $\mathrm{M}$ - mesiodens teeth group

concentration in enamel of the teeth from the control group was $0.72 \mathrm{wt} \%$ and in mesiodens enamel $0.35 \mathrm{wt} \%$. Magnesium concentration was statistically significantly higher in healthy enamel compared to mesiodens enamel $(P<0.05)$. The mean value of sodium concentration in healthy enamel was $0.58 \mathrm{wt} \%$ and in mesiodens enamel $0.61 \mathrm{wt} \%$. There was no statistically significant differencebetween the concentration of sodium in healthy enamel compared to mesiodens enamel $(P>0.05)$. When the concentration of calcium and phosphorus was considered, the experimental and control group of were significantly different, as well as carbon in enamel $(P<0.05)$ (Fig. 1).

The ratio of calcium and phosphorus concentration in healthy enamel was $1.97: 1$, whereas this ratio in mesiodens enamel was 2.26:1. Analysis of the ratio of calcium and carbon concentration in healthy enamel was 3.02:1 and the ratio of calcium and carbon concentration in mesiodens enamel was 1.53:1. Healthy and mesiodens enamel did not differ significantly in terms of statistics considering the ratio of calcium and phosphorus concentration $(P=0.083)$, whereas the ratio of calcium and carbon concentration was statistically significantly higher in healthy enamel compared to mesiodens enamel $(P=0.000)$ (Table 1).

\section{Dentine analysis}

Analysis of healthy dentine showed that the mean value of $\mathrm{Ca}$ concentration was $23.55 \mathrm{wt} \%$ whereas the mean value of calcium concentration in mesiodens dentine was $29.10 \mathrm{wt} \%$. It is shown that the concentration of calcium was significantly higher in mesiodens dentine compared to healthy dentin $(P<0.05)$. The mean value of phosphorus concentration in healthy dentine was 14.94 wt\% and in mesiodens dentine $10.59 \mathrm{wt} \%$. Phosphorus concentration was statistically significantly higher in healthy dentin compared to mesiodens dentine $(P<0.05$ ).The mean value of carbon concentration in healthy dentine was $11.93 \mathrm{wt} \%$ and in mesiodens dentine 19.78 wt $\%$. Carbon concentration was statistically significantly higher in mesiodens dentine compared to healthy dentine $(P<0.05)$. The mean value of magnesium concentration in healthy dentine was $0.76 \mathrm{wt} \%$ and in mesiodens dentine $0.60 \mathrm{wt} \%$. Magnesium concentration was statistically significantly higher in healthy dentine compared to mesiodens dentine $(P<0.05)$. The mean value of sodium
Table 2. Carbon content in wt\% in different zone of enamel of healthy and mesiodens teeth.

\begin{tabular}{lcc}
\hline Zone of enamel & \multicolumn{2}{c}{ Carbon (weight \%) } \\
& Healthy teeth & Mesiodens teeth \\
\hline Close to DEJ & $14.10 \pm 1.83$ & $39.20 \pm 3.64$ \\
Middle zone & $9.12 \pm 1.36$ & $15.58 \pm 1.94$ \\
Surface zone & $6.63 \pm 1.01$ & $7.14 \pm 1.14$ \\
Mean \pm SD & $9.95 \pm 1.40$ & $20.64 \pm 2.18$ \\
\hline
\end{tabular}

concentration in healthy dentine was $0.48 \mathrm{wt} \%$ and in mesiodens dentine $0.59 \mathrm{wt} \%$. Sodium concentration was not significantly higher in mesiodens dentine compared to healthy dentin $(P>0.05)$. The concentration of dentine calcium, phosphorus and carbon was significantly different between groups $(P<0.05)$ (Fig. 1).

The ratio of calcium and phosphorus concentration in the dentine of the teeth from the control group was $1.63: 1$, whereas the ratio of calcium and phosphorus concentration in mesiodens dentine was 2.78:1. Analysis of the ratio of calcium and carbon concentration in healthy dentine was 2.23:1, and the ratio of calcium and carbon concentration in mesiodens dentine was $1.48: 1$. Healthy and mesiodens dentine were statistically significantly different for ratio of calcium and phosphorus concentration $(P<0.05)$. The ratio of calcium and phosphorus concentration was statistically significantly higher in mesiodens dentine compared to healthy dentine. The ratio of calcium and carbon concentration was statistically significantly higher in healthy dentine $(P<0.05)$ (Table 1$)$.

\section{Cementum analysis}

Chemical elements analysis of healthy cementum showed that the mean value of $\mathrm{Ca}$ concentration was $29.62 \mathrm{wt} \%$ whereas the mean value of calcium concentration in mesiodens cementum was $24.54 \mathrm{wt} \%$. We observed that the concentration of calcium was significantly higher in healthy cementum compared to mesiodens cementum $(P<0.05)$. The mean value of phosphorus concentration in healthy cementum was $14.17 \mathrm{wt} \%$ while in mesiodens cementum was $12.47 \mathrm{wt} \%$. Phosphorus concentration was statistically significantly higher in healthy cementum compared to mesiodens cementum $(P<0.05)$. The mean value of carbon concentration in healthy cementum was $13.21 \mathrm{wt} \%$ and in mesiodens cementum $19.50 \mathrm{wt} \%$. 
Carbon concentration was statistically significantly higher in mesiodens cementum compared to healthy cementum $(P<0.05)$. The mean value of magnesium concentration in healthy cementumwas $0.28 \mathrm{wt} \%$ while in mesiodens cementum was $0.34 \mathrm{wt} \%$. Magnesium concentration was statistically significantly higher in mesiodens cementum compared to healthy cementum $(P<0.05)$. The mean value of sodium concentration in healthy cementum was 0.68 wt $\%$ and in mesiodens cementum $0.62 \mathrm{wt} \%$.There was no statistically significant difference between the concentration of sodium in healthy cementum compared to mesiodens cementum $(P>0.05)$. The cementum levels of $\mathrm{Ca}, \mathrm{P}$ and $\mathrm{C}$ were statistically significant between groups $(P<0.05)$ (Fig. 1).

Ratio of calcium and phosphorus concentration in healthy cementum was 2.10:1, whereas the ratio of calcium and phosphorus concentration in mesiodens cementum was 1.96:1. Analysis of the ratio of calcium and carbon concentration in healthy cementum was 2.25:1, and the ratio of calcium and carbon concentration in mesiodens cementum was $1.26: 1$. Healthy and mesiodens cementum did not differ significantly for calcium and phosphorus concentration $(P>0.05)$, whereas the ratio of calcium and carbon concentration was statistically significantly higher in healthy cementum compared to mesiodens cementum $(P<0.05)$ (Table 1$)$.

\section{DISCUSSION}

Scientific and clinical interest in supernumerary teeth and mesiodens has risen sharply in the last decade mostly due to reports in which researchers showed their successful clinical use in auto- and allo-transplantation procedures and identified these teeth as a good source of stem cells ${ }^{1-3}$. Previously, supernumerary teeth were considered mostly as an orthodontic and esthetic problem. Clinical utilization of these teeth in transplantation procedures potentiates the importance of the quality and durability of the hard dental tissues, especially in terms of their mineral content. In the available literature a number of the studies have been published on epidemiology, etiology and clinical manifestations associated with supernumerary teeth and mesiodens, but not on inorganic content ${ }^{5,8}$. In our study, the results showed that the concentration of calcium and phosphorus is higher in healthy enamel and cementum compared to mesiodens while in the dentine the calcium is higher, but phosphorus is lower. Nevertheless, overall the in incisors are very similar which is in correlation with the previous findings ${ }^{16,17}$. It is well known that when enamel ratio of $\mathrm{Ca} / \mathrm{P}$ is under 1,33 the tooth is more susceptible to decay, but in our investigation neither normal incisors, nor the mesiodens belong to that category $^{18,19}$. Our results showed a significant different in carbon content between groups. Analysis of the carbon concentration shows that the values are significantly higher in mesiodens enamel compared to healthy teeth, but regional distribution shows that concentration of mesiodens carbon abruptly decreases from the DEJ to the surface (with end-value very near to the normal teeth) which is in correlation to the previous findings ${ }^{7,20}$. This increased carbon presence in mesiodens is the result of persistence of remains of organic matter, probably due to alteration in maturation during which proteins are reabsorbed ${ }^{21}$. Bozal et al. ${ }^{21}$ and Jalevik et al. ${ }^{22}$ reported that decreased carbonate content strengthens the enamel. Crombie et al. ${ }^{23}$ claim that carbonate is a substitute for the phosphate group in the HAP. Normal or lower carbon concentration contributes to enamel hardness. One more conclusion is that mesiodens is not susceptible to accelerated decay although there are no comprehensive data on the incidence of the mesiodens caries ${ }^{24-26}$. In relation to the $\mathrm{Mg}$ differences found, magnesium is "trace" element that is absorbed, but not incorporated into the hydroxyapatite structure. Our results showed significantly (twice) lower amounts of magnesium in mesiodens enamel compared to normal teeth. Wychowański et al. ${ }^{27}$, suggest that magnesium is detrimental to enamel due to increased susceptibility to acid influence. We conclude that lower mesiodens enamel magnesium content in fact contributes to its resistance. This study showed increased calcium and decreased phosphorus content so the ratio of these elements is markedly in favor of calcium (up to 2.78:1). Our findings are in correlation with the report of Akgun et al. ${ }^{17}$ who found that mesiodens dentine is more calcified that normal dentine although exact values are at variance. On this matter we managed to find one very short report of Caihong et al. ${ }^{28}$ who stated the opposite, but our sample was larger. The dentinal $\mathrm{Ca} / \mathrm{C}$ ratio examination in our study showed that this ratio is lower in mesiodens than in healthy teeth, but the total amount of these elements was in fact increased. This is important because some authors claims that the very low carbon content in dentine may reduce its ability to withstand the mechanical pressure from the enamel, to become brittle and develop micro-cracks ${ }^{29,30}$. In a conclusion we can state that out study showed that, although there are some differences in overall mineral content and the ratio of the important inorganic elements of the hard tissues of the mesiodens and normal incisors, these differences are not highly significant. Therefore, auto- and allotransplantation of mesiodens is valid given that durability is similar to normal teeth.

Acknowledgement: This research was supported by JP 02/17 of the Faculty of Medical Sciences, University of Kragujevac, Serbia.

Author contributions: All authors participated in gathering information and samples for the work, design of experiment, review of the literature, writing, statistical analysis and manuscript revision.

Conflict of interest statement: The authors declare there are no conflicts of interest regarding the publication of this article.

\section{REFERENCES}

1. Tirali R, Sar C, Ates U, Kizilkaya M, Cehreli B. Autotransplantation of a supernumerary tooth to replace a misaligned incisor with abnormal dimensions and morphology:2-year follow-up. Case Rep Dent 2013;2013:1-5. doi: 10.1155/2013/146343 
2. Pai SM, Patil PS, Poornima P, Subbareddy VV. Mesiodens used for allotransplantation. Eur J Gen Dent 2013;2:178-81. doi: 10.4103/22789626.112324

3. Lee S, An S, Kang TH, Kim KH, Chang NH, Kang S, Kwak CK, Park HS. Comparison of mesenchymal-like stem/progenitor cells derived from supernumerary teeth with stem cells from human exfoliated deciduous teeth. Regen Med 2011;6(6):689-99. doi: 10.2217/ rme.11.95

4. Marinelli A, Giuntini V, Franchi L, Tollaro I, Baccetti T, Defraia E. Dental anomalies in the primary dentition and their repetition in the permanent dentition: a diagnostic performance study. Odontology 2012;100:22-7. doi: 10.1007/s10266-011-0021-6

5. Mínguez-Martinez I, Ata-Ali J, Bonet-Coloma C, Peñarrocha-Oltra D, Peñarrocha-Diago MA, Minguez-Sanz JM. Management and outcome following extraction of 303 supernumerary teeth in pediatric patients. Pediatr Dent 2012;34:136-9.

6. Subasioglu A, Savas S, Kucukyilmaz E, Kesim S, Yagci A, Dundar $M$.Genetic background of supernumerary teeth. Eur J Dent 2015;9(1):153-8. doi: 10.4103/1305-7456.149670

7. Torabinejad M, Walton RE. Endodontics: Principles and Practice 5thSt. Louis, Missouri: Elsevier 2015.

8. Ata-Ali F, Ata-Ali J, Peñarrocha-Oltra D, Peñarrocha-Diago M Prevalence, etiology, diagnosis, treatment and complications of supernumerary teeth. J ClinExp Dent 2014;6(4):e414-8. doi: 10.4317/ jced.51499

9. Wang XP, Fan J. Molecular genetics of supernumerary tooth formation. Genesis2011;49(4):261-77. doi: 10.1002/dvg.20715

10. Subasioglu A, Savas S, Kucukyilmaz E, Kesim S, Yagci A, Dundar $M$.Genetic background of supernumerary teeth. Eur J Dent 2015;9(1):153-8. doi:10.4103/1305-7456.149670

11. Roberto Pippi .Odontomas and Supernumerary Teeth: Is There a Common Origin? Int J Med Sci 2014;11(12):1282-97. doi: 10.7150/ ijms.10501

12. MonishaP.Khatri, Samuel V. Overview of mesiodens - A review. Int J Pharm Bio Sci 2014; 5(2):526-39.

13. Gonçalves PF, Sallum EA, Casati MZ, Toledo SD, Junior FH. Dental cementum reviewed: development, structure, composition, regen eration and potential functions. Braz J Oral Sci 2005;4(12):651-8. doi: 10.20396/bjos.v4i12.8641790

14. Fagrell TG, Dietz W, Jälevik B, Norén JG. Chemical, mechanica and morphological properties of hypomineralized enamel of permanent first molars. Acta Odontol Scand 2010;68(4):215-22. doi 10.3109/00016351003752395

15. Cakir FY, Korkmaz Y, Firat E, Oztas SS, Gurgan S. Chemical Analysis of Enamel and Dentin Following the Application of Three Different At-home Bleaching Systems. Operative Dentistry 2011;36(5):529-36. doi: 10.2341/11-050-L

16. Arnold WH, Gaengler P. Quantitative analysis of the calcium and phosphorus content of developing and permanent human teeth. Ann Anat 2007;189(2):183-90. doi: 10.1016/j.aanat.2006.09.008
17. Akgun OM, Bayari SH, Ide S, Polat GG, Kalkhoran IO. Micro- and Nanoscale Structures of Mesiodens Dentin: Combined Study of FTIR and SAXS/WAXS Techniques. Microsc Res Tech 2015;78(1):52-8. doi: 10.1002/jemt.22444

18. Alvarez-Pérez MA, Alvarez-Fregoso O, Ortiz-López J, Arzate H. X-Ray Microanalysis of Human Cementum. Microsc. Microanal 2005;11:313-8. doi: 10.1017/S1431927605050221

19. Gutiérrez-Salazar MP, Reyes-Gasga J. Microhardness and chemical composition of human tooth. Materials Research 2003;6(3):367-73. doi: 10.1590/S1516-14392003000300011

20. Spizzirri PG, Cochrane NJ, Prawer S, Reynolds EC. A comparative study of carbonate determination in human teeth using Raman spectroscopy. Caries Res 2012;46(4):353-60. doi: 10.1159/000337398

21. Bozal CB, Kaplan A, Ortolani A, Cortese GS, Biondi MA.Ultrastructure of the surface of dental enamel with molar incisor hypomineralization with and without acid etching. Acta Odontol Latinoam 2015:28(2):192-8. doi: 10.1590/S1852-48342015000200016

22. Jalevik B, Noren JG. Enamel hypomineralization of permanent first molars: A morphological study and survey of possible aetiological factors. Int J Paediatr Dent 2000;10(4):278-89. doi: 10.1046/j.1365263x.2000.00210

23. Crombie FA, Manton DJ, Palamara JE, Zalizniak I, Cochrane NJ, Reynolds EC. Characterisation of developmentally hypomineralised human enamel. J Dent 2013;41(7):611-8. doi: 10.1016/j. jdent.2013.05.002

24. Xu C, Reed R, Gorski PJ, Wang Y, WalkerPM. The Distribution of Carbonate in Enamel and its Correlation with Structure and Mechanical Properties. J Mater Sci 2012;47(23):8035-43. doi: 10.1007/s10853-012-6693-7

25. Ippolitov AY, Ippolitov IY, Seredin P.V. Morphology of the human dental enamel. Indian journal of dentistry 2014;5(suppl):135-9. doi: 10.1016/j.ijd.2014.03.004

26. Amr AM, Fattah A, Helal I. Analysis of Trace Elements in Teeth by ICPMS: Implications for Caries. Journal of Physical Science 2010;21(2):112.

27. Wychowański P, Wojtowicz A, Stawicka-Wychowańska R, Roszkowski W, Kalinowski E. Morphological Analysis of Dentin of the supernumerary and additional teeth. Nowa Stomatologia 2004;1:3-6.

28. CaihongY, Lihong G, Yan G,Shuzhen P, Dengcheng W. Histology and morphology between supernumerary tooth and normal tooth . Journal of Modern Stomatology 2002;3:270-1.

29. Pavlova VT, Nesterov VA, Lubov A. Pavlova LA, Peshkova KE. Study of Mineral Composition and Morphology of Hard Tissue of Teeth in Patients with Thyroid Gland Pathology in Russia, Belgorod Region. Research Journal of Medical Sciences 2015;9(4):256-62. doi: 10.3923/ rjmsci.2015.256.262

30. Boskey AL, Mendelsohn R. Infrared spectroscopic characterization of mineralized tissues. VibSpectrosc 2005;38:107-14. doi: 10.1016/j. vibspec.2005.02.015 